\title{
Commentary: Comprehensive Treatment with Chinese Medicine in Patients with Advanced Non-Small Cell Lung Cancer
}

\author{
Yingtian Wang, Ying Zhang, Jie Liu, Huiting Fan, Xueqian Wang, Hong-sheng Lin*
}

Department of Oncology, Guang'anmen Hospital, China Academy of Chinese Medical Sciences, Beijing, China

Article Info

\section{Article Notes}

Received: June 13, 2018

Accepted: January 21, 2019

\section{*Correspondence:}

Dr. Hong-sheng Lin, Department of Oncology, Guang'anmen Hospital, China Academy of Chinese Medical Sciences,

Beijing (100053),China; E-mail: drlinhongsheng@163.com.

(C) 2019 Lin SH. This article is distributed under the terms of the Creative Commons Attribution 4.0 International License.

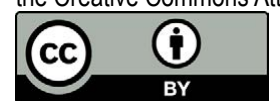

\section{The origin and development of CM oncology research}

The conception and method of treating cancer with Chinese Medicine (CM) could be traced back to ancient scriptures recorded 2,000 years ago $^{1}$. In the 1960 s, the older generation of CM physicians screened effective herbs based on clinical experience ${ }^{2}$ Not until the 1980s, the advantages of CM in relieving the side effects of chemotherapy and radiotherapy were generally recognized and applied $^{3}$. A comprehensive treatment strategy, integrating CM with Western Medicine (WM) was preliminarily formed. Until the 1990s, scientists initiated to investigate the mechanism and efficacy of CM through experiments and clinical trials on the foundation of years of applications ${ }^{4-7}$. Gradually, with the development of evidencebased medicine, more and more evidence-based clinical trials were conducted by comprehensive medical centers, which showed positive results in prolonging survival and improving the quality of life ${ }^{8,9}$. In this way, the principle of CM cancer treatment was settled, that is, a combination of strengthening the healthy qi and eliminating pathogenic factors. Consequently, on the fundamental of evidencebased results, a comprehensive treatment strategy was determined based on experts' consensus; furthermore, a CM oncology clinical treatment guideline was established and published with the help of multiple-field specialists ${ }^{10}$. Eventually, all these efforts contributed to a standardized scheme that would currently be applied in China.

Why is it difficult for CM to become a part of the international guideline for cancer treatment?

Despite all the progress mentioned above, the clinical application of CM in cancer is still difficult to be widely accepted and used. CM has a unique characteristic based on its independent philosophical theory; meanwhile, individualized treatment based on syndrome differentiation is intensely appreciated, which means specific treatment measures largely vary on different cases, making it difficult to be understood and used. Besides, as CM functions slowly and acts on multi-targets ${ }^{11}$, observing its short-term efficacy is difficult, and a comprehensive treatment strategy is necessary. All these problems restricted the process of $\mathrm{CM}$ evidence-based development and generalization.

What have we done to solve these problems?

In conclusion, the use of $\mathrm{CM}$ in cancer treatment requires higher levels of medical evidence and concise usage instructions. CM can be standardly and globally used if these two goals are achieved. In the recent cohort study on a comprehensive treatment of advanced non-small cell 
lung cancer (NSCLC), we would like to report our ways of using the standardized comprehensive treatment scheme and results, to provide a reference for $\mathrm{CM}$ usage instruction and efficacy evidence for the treatment of advanced NSCLC.

\section{How can a standardized CM treatment strategy be applied clinically?}

To determine whether additional CM could prolong survival in patients with advanced NSCLC, we conducted a multiple centers, prospective cohort study. Patients were divided into two groups, in the WM group, patients received radiotherapy, chemotherapy, and optimal supportive therapy according to the National Comprehensive Cancer Network (NCCN) guidelines. The integrative medicine (IM) group patients were administered with both individualized CM (Chinese patent medicines and injections) and WM.

In this cohort study, the WM group received therapy according to the NCCN guidelines. The first-line protocols used for chemotherapy included vinorelbine/cisplatin, paclitaxel/cisplatin, paclitaxel/carboplatin, gemcitabine/ cisplatin, and gemcitabine/carboplatin. The second- and third-line protocols included docetaxel and pemetrexed. Meanwhile, the IM group followed the same guidelines with an individualized CM treatment.

An individualized CM treatment was coordinated with WM treatment and syndrome identification of patients, recognized by a collaborative group consisted of multiplefield experts. Chinese patent medicines, injections, and formula constituted the whole CM treatment strategy. During chemotherapy, three methods were used to reduce adverse effects, such as tonify qi and replenish blood, tonify Pi (spleen) and harmonize Wei (stomach), enrich Shen (kidney), and nourish Gan (Liver) .While patients were undergoing radiotherapy, CM was administered to enrich the yin and engender fluids, which activate and detoxify the blood. After the completion of radiotherapy/ chemotherapy, tonify qi and promote blood circulation and detoxification methods were used according to the CM guidelines. All the orally taken or injected CM patents used are listed in Table 1.

Table 1.Treatment methods and recommend CM patents

\begin{tabular}{|c|c|c|c|c|}
\hline \begin{tabular}{|l|} 
Intervention \\
time / Efficacy
\end{tabular} & \begin{tabular}{|l|} 
Treatment \\
methods
\end{tabular} & $\begin{array}{l}\text { Name of the } \\
\text { medicine }\end{array}$ & Usage & $\begin{array}{l}\text { Herbal } \\
\text { constituent }\end{array}$ \\
\hline \multirow{5}{*}{$\begin{array}{l}\text { During } \\
\text { Chemotherapy/ } \\
\text { protective } \\
\text { Chinese medical } \\
\text { therapy }\end{array}$} & \multirow{3}{*}{$\begin{array}{l}\text { Supplements qi and } \\
\text { consolidates the body }\end{array}$} & Kang Ai Zhu She Ye & 40-60ml+250ml NS, ivgtt qd & Astragalus, ginseng, matrine \\
\hline & & $\begin{array}{l}\text { Shen Qi Fu Zheng } \\
\text { Zhu She Ye }\end{array}$ & $250 \mathrm{ml} \mathrm{ivgtt} \mathrm{qd}$ & Radix Codonopsis, Radix Astragali \\
\hline & & $\begin{array}{l}\text { Zhen Qi Fu Zheng } \\
\text { JiaoNang/KeLi }\end{array}$ & $5 \mathrm{~g}$, twice daily & Astragalus, Joan \\
\hline & $\begin{array}{l}\text { Strengthens the spleen and } \\
\text { benefits the kidney }\end{array}$ & Jian Pi Yi Shen Ke Li & $10 \mathrm{~g}$, twice daily & $\begin{array}{l}\text { Codonopsis pilosula, Lycium barbarum, } \\
\text { Ligustrum lucidum, Atractylodes } \\
\text { macrocephala, Cuscuta chinensis and Fructus } \\
\text { psoraleis (salt processed) }\end{array}$ \\
\hline & $\begin{array}{l}\text { Supplements qi and } \\
\text { nourishes yin }\end{array}$ & Sheng Xue Wan & $5 \mathrm{~g}$, thrice daily; & $\begin{array}{l}\text { Velvet antler, Cortex Phellodendri, Rhizoma } \\
\text { Atractylodis Macrocephalae (stir fried), } \\
\text { Chinese yam, placenta, mulberry sticks, fried } \\
\text { white lentils, and rice sprouts. }\end{array}$ \\
\hline \multirow[t]{2}{*}{$\begin{array}{l}\text { During } \\
\text { Radiotherapy } \\
\text { /protective } \\
\text { Chinese medical } \\
\text { therapy }\end{array}$} & \multirow{2}{*}{$\begin{array}{l}\text { Nourishes yin, clears } \\
\text { heat, supplements qi and } \\
\text { regenerates blood }\end{array}$} & $\begin{array}{l}\text { Yang Yin Sheng Xue } \\
\mathrm{He} \mathrm{Ji}\end{array}$ & $\begin{array}{l}50 \mathrm{ml} \text {, once daily, } 1 \mathrm{~h} \text { before } \\
\text { radiotherapy; } 25 \mathrm{~mL} \text {, twice } \\
\text { daily, after radiotherapy; }\end{array}$ & $\begin{array}{l}\text { Radix rehmanniae, Radix Astragali, Radix } \\
\text { Angelicae sinensis, Radix Astragali, Radix } \\
\text { Ophiopogon, Dendrobium and Ligusticum } \\
\text { chuanxiong Hort. }\end{array}$ \\
\hline & & Anduolin Capsule & $1.28 \mathrm{~g}$, thrice daily; & Lignum millettiae \\
\hline \multirow{5}{*}{$\begin{array}{l}\text { After Radio- } \\
\text {,chemo-therapy } \\
\text { / Consolidation } \\
\text { Chinese medical } \\
\text { therapy }\end{array}$} & $\begin{array}{l}\text { Resolves stasis and promotes } \\
\text { urination }\end{array}$ & Lanxiangxi Injection & $\begin{array}{l}0.4-0.6+5 \% G S 500 \mathrm{ml} \mathrm{ivgtt} \\
\text { qd; }\end{array}$ & Extraction of Curcuma Aromatica \\
\hline & \multirow{2}{*}{$\begin{array}{l}\text { Clears heat, removes toxins, } \\
\text { resolves phlegm and softens } \\
\text { masses }\end{array}$} & Xiaoaiping Injection & $\begin{array}{l}\text { 20-100mL+5\%GS 250ml } \\
\text { ivgtt qd; }\end{array}$ & Rattan \\
\hline & & $\begin{array}{l}\text { Fufang Kushen } \\
\text { Injection }\end{array}$ & $\begin{array}{l}12 \mathrm{~mL}+0.9 \% \mathrm{NS} 200 \mathrm{ml} \text { ivgtt } \\
\mathrm{qd} ;\end{array}$ & Radix sophorae, flavescentis \\
\hline & $\begin{array}{l}\text { Supplements qi, nourishes } \\
\text { yin, resolves stasis and } \\
\text { disperses masses }\end{array}$ & Kanglaite Injection & $200 \mathrm{ml}$ ivgtt qd; & Semen coicis \\
\hline & $\begin{array}{l}\text { Supplements qi, nourishes } \\
\text { yin, clears heat, removes } \\
\text { toxins, resolves phlegm and } \\
\text { stops coughing }\end{array}$ & $\begin{array}{l}\text { Yifei Qinghua } \\
\text { Granules }\end{array}$ & $20 \mathrm{~g}$ orally taken, thrice daily; & $\begin{array}{l}\text { Astragalus membranaceus, Codonopsis } \\
\text { pilosula, Radix Astragali, Radix Glycyrrhizae, } \\
\text { Ophiopogon japonicus, Herba Sinensis, Herba } \\
\text { Patriniae, Herba Hedyotis diffusae, Fritillaria, } \\
\text { Aster, Platycodon grandiflorum, Almond bitter, } \\
\text { Licorice }\end{array}$ \\
\hline
\end{tabular}


In order to provide a better understanding and clear instruction for clinical physicians, we have made an Integrative Chinese and Western medical treatment approach for advanced NSCLC (Figure 1), and a syndrome differentiation method (attachment1). Under the application of CM treatment strategy the following results were obtained.

\section{Comprehensive treatment with $\mathrm{CM}$ could prolong survival and improve prognosis}

A total of 474 hospitalized patients with stage III-IV NSCLC from 12 centers were recruited. During the followup period,253 patients (53.38\%) died and 319 patients $(67.30 \%)$ had disease progression. We have followed up for 3 years, finally result showed that the median survival was 16.60 months in the IM group compared with 13.13 months in the WM group $(\mathrm{P}<0.01)$, the difference was statistically significant. Cox regression analysis indicated cohort, stage and ECOG score affected the prognosis, proved the significant role in prolonging survival of integrative treatment. What's more, better ECOG scores was also observed in IM group, with $10.11 \%$ increased $(7.14 \%$ in WM group) and $83.5 \%$ kept stable (73.98\% in WM group).

The efficacy of radio- and chemotherapy wouldn't be reduced by CM

The ORR(Objective Response Rate) and DCR(Disease Control Rate) in the IM group were $24.36 \%$ and $56.48 \%$,higher than those in the WM group $(15.29 \%$ and 41.17\%),but had no significant differences between two groups $(\mathrm{P}>0.05)$. Although there was no statistics could illustrate the interaction relationship between $\mathrm{CM}$ and $\mathrm{WM}$, there were no signs of any negative impact in this trial.

\section{Adverse effects of radio- and chemotherapy could be attenuated by $\mathrm{CM}$ with reliable security}

Generally, treatment efficacy of radiotherapy and chemotherapy always accompanied with adverse effect. In the IM group, the incidences of anorexia, nausea, and vomiting were significantly lower than those in the WM group $(\mathrm{P}<0.01)$. The most common AEs was myelosuppression. The incidence of grade 3 neutropenia was $13.64 \%$ in the WM group and $9.82 \%$ in the IM group, and serious AEs and treatment-related death were not observed.

\section{QOL could be improved with relief of physical and mental symptoms by $\mathrm{CM}$.}

The QOL based on Functional Assessment of Cancer Therapy-Lung in the IM group was markedly higher than that in the WM group for the fourth course $(\mathrm{P}<0.05)$. In the IM group, QOL evaluated with FACT-L increased after 4 courses of therapy compared with the baseline (86.16 \pm 13.49 vs. $85.05 \pm 12.86, P=0.2182$ ), while FACT-L score decreased significantly in the WM group $(83.89 \pm 11.03$ vs. $80.43 \pm 11.89, \mathrm{P}<0.0001)$.A significantly greater overall improvement in FACT-L scores was observed among patients who received IM compared with patients in the WM group $(\mathrm{P}<0.0001)$.

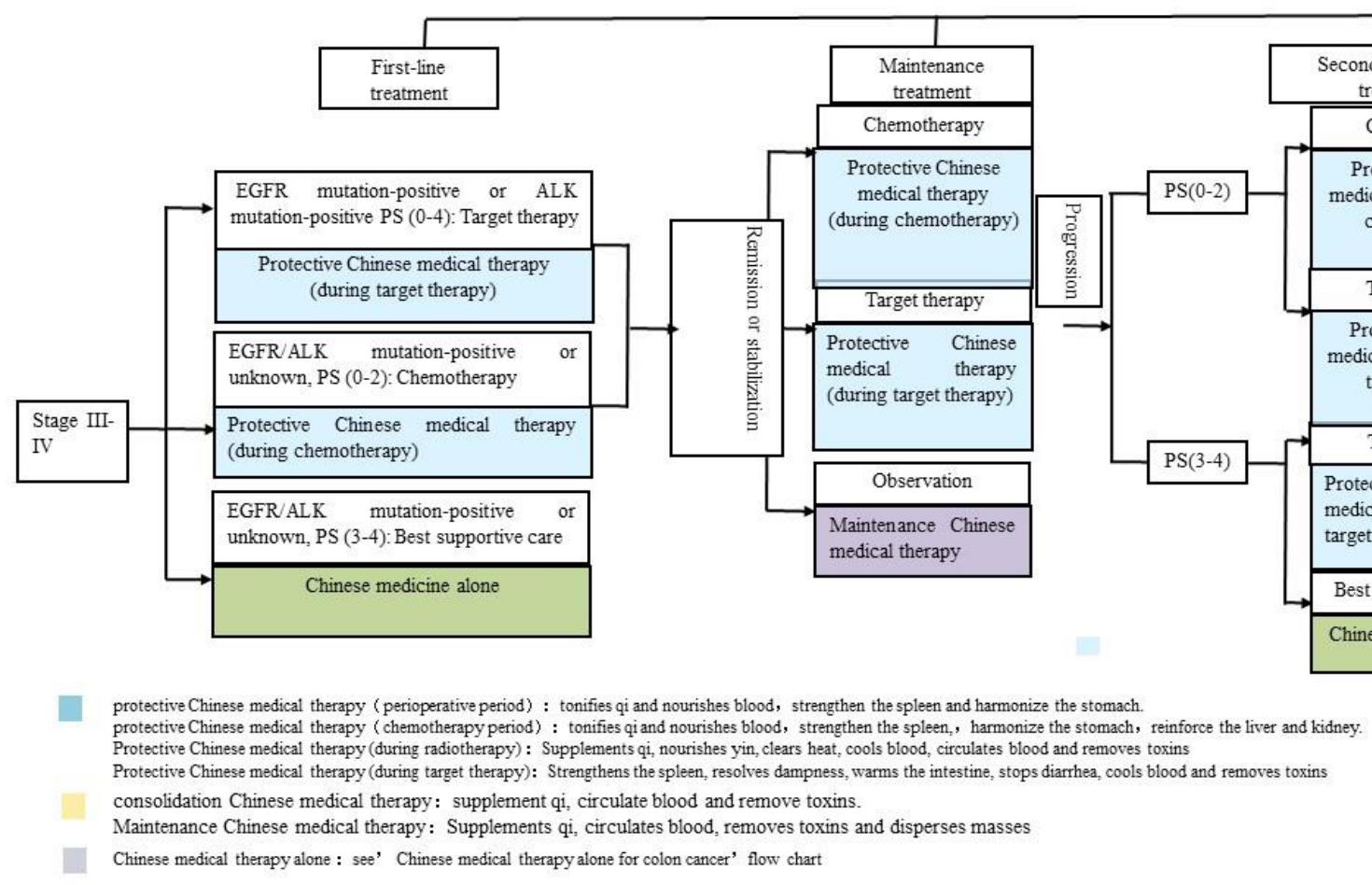

Figure 1: 
CM can be standardized and widely used in the treatment of advanced NSCLC patients, benefit survival and prognosis.

Basing on these investigation data, here comes a conclusion.CM can be standardized and widely used in the treatment of advanced NSCLC patients, benefit survival and prognosis. The standardized comprehensive treatment scheme is the prerequisite for curative effect and application.

\section{What can we do in the future?}

Cohort studies are of higher rank among all the evidence-based medical researches, just lower than RCT and meta-analysis ${ }^{12}$. This study divided advanced nonsmall cell lung cancer patients into two groups according to whether exposure to CM treatment, and have kept tracking of the observed outcomes in two groups for 3 years, compared the differences of outcomes between groups, so as to determine any causal connection between exposure factors and the target outcome, analysis the degree of correlation. Compared with RCT studies, cohort studies can demonstrate causality, and the subjects included in the analysis is more manifold and representative, which means a better application value. As targeted medicine and immune agents have not been wildly used when this study was designed. Targeted drug therapy and immune therapy were without inclusion. This is the deficiency of our work and the future research direction. By now, with the registration of clinical research, more and more TCM physicians have realized the importance of evidence-based medical research. However, the application of standardized treatment of CM still exists many problems. We need to keep updating and enriching the guide in the future work, base on the more higher level of evidence-based medical evidence for CM treatment, contribute to a foundation for its standardization and globally application.

\section{References}

1. Wu-ming Liu. Huangdi Neijing.Zhongnan University: 2007.

2. Yeh SD. Anticancer Chinese herbal medicines. Am J Chin Med (Gard City N Y). 1973 Jul; 1(2): 271-4

3. Cha RJ. Combined modality treatment of small cell lung cancer by chemotherapy, radiotherapy, immunotherapy and Chinese traditional medicine. Zhonghua Jie He He Hu Xi Za Zhi. 1989 Feb; 12(1): 41-4, 63.

4. Zhou BN. Some progress on the chemistry of natural bioactive terpenoids from Chinese medicinal plants. Mem Inst Oswaldo Cruz. 1991; 86 Suppl 2: 219-26.

5. Wong BY, Lau BH, Teel RW. Chinese medicinal herbs modulate mutagenesis, DNA binding and metabolism of benzo[a]pyrene 7,8-dihydrodiol and benzo[a]pyrene 7,8-dihydrodiol-9,10-epoxide. Cancer Lett. 1992 Feb 29; 62(2): 123-31.

6. Xin YL. Traditional and Western medical treatment of 211 cases of late stage lung cancer. Zhongguo Zhong Xi Yi Jie He Za Zhi. 1993 Mar; 13(3): 135-8, 131. Chinese.

7. Lin HS, Li DR. Multi-center randomized clinical study on Shenqifuzheng injection combined with chemotherapy in the treatment for lung cancer. Zhonghua Zhong Liu Za Zhi. 2007 Dec; 29(12): 931-4.

8. Liu J, Lin HS, Hou W, et al. Comprehensive treatment with Chinese medicine in patients with advanced non-small cell lung cancer: A multicenter, prospective, cohort study. Chin J Integr Med. 2017 Oct; 23(10): 733-739.

9. Sun $Y$, Lin $H, Z$ Zhu Y, et al. A randomized, prospective, multi-centre clinical trial of NP regimen (vinorelbine+cisplatin) plus Gensing Rg3 in the treatment of advanced non-small cell lung cancer patients. Zhongguo Fei Ai Za Zhi. 2006 Jun 20; 9(3): 254-8.

10. Lin HS. Clinical Practice Guidelines of Chinese Medicine in Oncology. People's Medical Publishing House: 2016.

11. Li J, Lin HS. Integrative medicine: a characteristic China model for cancer treatment.Chin J Integr Med. 2011 Apr; 17(4): 243-5.

12. Wang JL. Clinical epidemiology.Shanghai Scientific and Technical Publishers: 2009. 